Dr Charlie Brooker, Regional Nurse (Research), Trent Health, challenged this conclusion. Compliance could be substantially improved in the target group of psychotic patients if community psychiatric nurses were better trained. Some of the pressure for a CTO may come from a failure to target adequately trained services on the seriously mentally ill. Such skills, he said, would not be obtained from within traditional nurse training.

Dr Tom Sensky compared 'extended leave' patients, those 'nominated' as being suitable for a CTO and a control group judged not to need it. He concluded that reliable, clinical identification of the target group was possible. American experience of CTOs, however, was not universally reassuring.

This complex session was made even more challenging by Phill Fennell, Lecturer in Law at Cardiff. After a detailed overview of historical precedents to a CTO and their often completely unanticipated consequences, he responded to the draft proposals outlined by Professor Bluglass. The Mental Health Review Tribunal is, he contended, unique in that the burden of proof is on the patient or his advocate to establish why he should be set free. Given this unusual configuration of the MHA Tribunal he felt that the proposed CTO could be in conflict with Article 5 of the European Convention on Human Rights if a patient who had not, as yet, deteriorated were to be recalled to hospital.

Considerable concern was expressed that CTOs should not be seen as a cheap alternative to comprehensive community services. The attitudes of the voluntary sector and users groups were clearly crucial but confusing at present and it was important not to risk good relations with them for a numerically very small patient group.

The conference was marked by the lively debate engendered by the differing viewpoints of the three sections on issues of intense importance to all of them. The presence of a large group of SRs for such a meeting also supplied vigour.

\section{Reference}

Review of Health and Social Services for Mentally Disordered Offenders and Others Requiring Similar Services. Final Summary Report. HMSO, London, 1992. Command Number 2088. $£ 12.40$.

\title{
European Association for Mental Health in Mental Retardation*
}

\author{
N. BouRAS, Division of Psychiatry, Guy's Hospital, London SE1 9RT
}

Delegates from 13 European countries attended the inaugural meeting of the European Association for Mental Health in Mental Retardation in The Netherlands.

The theme of the conference was current advances, practices and service developments for people with mental retardation and psychiatric disorders. Despite the fact that most European countries haveadopted the principles of "normalisation" and "social integration" for services for people with mental retardation, great differences still exist between them in their approach to care. The differences are mainly associated with organisational difficulties, professional ideology and approach and cultural aspects and beliefs.

With the exception of very few countries where there is an organised system of services for people

Conference held on 8-9 October 1992 in Veldhoven, The Netherlands. with mental retardation and psychiatric disorders, most European countries have not achieved an optimum level of care. Instead, there have been rather isolated initiatives, pioneered either by individuals or organisations. The newly formed European Association aims to ameliorate the problems through international collaboration, joint programmes, conferences and research projects. The experience gained from North America through the activities of the National Association for the Dually Diagnosed, whose representatives were also present, would be taken into consideration and would be beneficial.

The members of the Executive Committee are A. Dosen (Netherlands), K. Day (UK), W. Verhoeven (Netherlands), C. Gaedt (Germany) and M. Van Wallenghem (Belgium). Further information can be obtained from: Dr A. Dosen, Nieuw Spraeland, Postbus 5029, 5800 GA Venray, Netherlands. 